\title{
Regional programs as instrument of reducing of poverty for sustainable development of Russia
}

\author{
Vladimir Smirnov ${ }^{1,2}$, Marina Danilina ${ }^{1,2,3,{ }^{*}}$, Olga Selivanova ${ }^{1}$, Ludmila $_{\text {Botasheva }}{ }^{2}$, and \\ Natalia Kabanova ${ }^{2}$ \\ ${ }^{1}$ Research Institute VNII of Labor, Ministry of Labour of Russia, Zemlyanoy Val, 34, 105064 \\ Moscow, Russia \\ ${ }^{2}$ Finance University under the Government of the Russian Federation, Leningradsky prosp., 49, \\ 125993 Moscow, Russia \\ ${ }^{3}$ Plekhanov Russian University of Economics (PRUE), Stremyanny per., 36, 117997 Moscow, Russia
}

\begin{abstract}
The article is dedicated to the analysis of the regional programs as an instrument of diminishment of poverty level in the regions of Russia. On the basis of the examination of 14 regional programs, in accordance with the methodology, developed by VNII of Labour, it was found that the goals of all regional programs are aimed at a steady increase in the income of citizens and a decrease in the proportion of the population with incomes below the subsistence level. Despite the existing variability of formulations, according to the semantic load, the tasks of all regional programs can be combined into four blocks: increase in the level of income of citizens and an excess of the growth rate of income of citizens, including average wages, over the rate of growth of inflation; development of a system of social assistance to citizens in need; development of the social contract system; organization of social adaptation of low-income citizens.
\end{abstract}

\section{Introduction}

Poverty is one of the important problems of the contemporary world. The basic definition of poverty is that the poor cannot meet basic life needs. However, the composition of "basic living needs" can include various indicators for different states and population groups. In the Russian Federation, the definition of poverty is used, when the poor people are defined as persons with an income below the subsistence minimum level. This leads to a situation where a significant proportion of families with income slightly above the subsistence level cannot receive social support despite the fact that their standard of living does not differ from the citizens, officially recognized as poor.

In foreign countries, there are several methods for determining the level of poverty. They can be divided into two large groups - by absolute and relative boundaries. As an absolute poverty line, the amount of income is used, necessary to buy a consumer basket in goods and services, necessary to meet the physiological needs of the body. Poor is an individual who is unable to provide himself with consumption of such a basket. The share of average or median

${ }^{*}$ Corresponding author: marinadanilina@yandex.ru 
income is used as a relative poverty line. An individual whose income is less than this share is considered poor.

Each approach has its own advantages and disadvantages. The advantages of the absolute poverty line method include:

1) ease of establishing the line - since the absolute poverty line is established on the basis of the average biological indicators of the human body, then it is objective;

2) simplicity of calculating the number of the poor - any citizen whose income is below the established minimum falls into the number of poor

The disadvantages of the absolute method include:

1) incompleteness of the information received about the poor - since not all the poor receive income below the established absolute poverty line, the information received on the number of poor citizens will not be complete, which will not allow providing social support to everyone who needs it;

2) low level of the border - since the absolute level of poverty is based on physiological indicators, it provides the minimum border of the citizen's survival;

3) lagging behind the price level - since the indexation of the absolute level of poverty occurs after the fact, it lags behind the rise in prices for the size of inflation.

Compensation for these shortcomings is intended to provide a relative poverty line. As a rule, it is formed as a certain share of the median income indicator in a country or region.

The advantages of this method include:

1) setting the poverty line at a level sufficient to maintain a standard of living above physiological norms;

2) the ability to take into account the intangible needs of a person;

3 ) the possibility of automatic change in the relative poverty line in connection with the change in the economic situation in the state.

The disadvantages of this method include:

1) the complexity of use in poor countries, since the level of the median income there is low and the share of the median income is below the absolute poverty line;

2) the difficulty of establishing the relative poverty line due to the difficulty of determining the required share of the median or average income.

Currently, it is customary among foreign countries to combine these two approaches. Their combined use allows you to fully reveal the advantages of each method, while compensating for the disadvantages.

\section{Materials and methods}

Decree of the President of the Russian Federation of July 21, 2020 No. 474 "On the national development goals of the Russian Federation for the period up to 2030" among the main national development goals of the country identified the provision of sustainable growth in real incomes of citizens, a decrease in the proportion of the population with incomes below the subsistence level, one of the most important the country's objectives and an indicator of the achievement of national goals is the reduction of the poverty level by half compared with the indicator of 2017.

To achieve these goals, the executive authorities of the constituent entities of the Russian Federation develop state regional programs to reduce the proportion of the population with incomes below the subsistence level. When developing regional programs, the constituent entities of the Russian Federation create appropriate working bodies whose tasks are to analyse the current situation related to the standard of living of the population in the constituent entity of the Russian Federation, identify the causes and characteristics of poverty in the constituent entity of the Russian Federation, determine the target values of the indicator "Poverty rate" in accordance with the Methodology for calculating the poverty rate indicator 
for the period up to 2030 inclusive, approved by the Decree of the Government of the Russian Federation No. 915 of July 17, 2019, the development of measures to achieve the target value of the indicator "Poverty rate", the development of mechanisms for organizing interagency cooperation, approval of the regional program at the level of the constituent entity of the Russian Federation.

VNII of Labour received 17 approved regional programs. Of these, 14 regional programs were analysed in order to reduce the share of the population with incomes below the subsistence level in 8 federal districts (Altai Territory (Siberian Federal District), Voronezh Region (Central Federal District), Irkutsk Region (Siberian Federal District), Kirov Region (Volga Federal District) ), Novgorod Region (North-West Federal District), Oryol Region (Central Federal District), Pskov Region (North-West Federal District), Republic of Mordovia (Volga Federal District), Rostov Region (South Federal District), Tyumen Region (Ural Federal District), Penza Region (Privolzhsky Federal District), Magadan Region (Far Eastern Federal District), Stavropol Territory (Southern Federal District), Republic of Bashkortostan (Volga Federal District).

In accordance with the methodology, developed by VNII of Labour, the analysis was carried out. This analysis of the compliance of the goals and objectives of regional programs with the conditions for achieving the target "poverty reduction" showed the following. In the course of the expertise of regional programs, it was found that the goals of all regional programs are aimed at a steady increase in the income of citizens and a decrease in the proportion of the population with incomes below the subsistence level. For example, the goal of the regional program of the Altai Territory is "to ensure sustainable growth of incomes of citizens and to halve the poverty level in the Altai Territory by 2030 relative to 2017". The objectives of the regional program of the Penza region are: "Sustainable growth of real money incomes of the population in the Penza region"; "Reducing the poverty level in the Penza region by half by 2030". The goal of the regional program of the Magadan region is "Ensuring a stable growth in real disposable incomes of the population of the Magadan region and reducing the proportion of the population with incomes below the subsistence level in the Magadan region."

At the same time, the implementation of a number of regional programs (Irkutsk region, Novgorod region, Oryol region, Republic of Bashkortostan) is designed for the period 20202024, which impedes the achievement of the target "Reducing the poverty level by half compared to 2017" by 2030 and requires revising and adjusting the above programs.

To achieve these goals, most regional programs define tasks, the implementation of which is aimed at increasing the income of citizens and reducing the proportion of the population with incomes below the subsistence level. For example, in the regional program of the Rostov region the following tasks are formulated: "Raising the level of incomes of citizens and ensuring that the growth rate of average wages is not lower than the growth of inflation", "Creation of conditions for sustainable economic growth in order to improve the welfare of the population", "Development of a system of social assistance to citizens in need", "Development of a social contract system", "Organization of social adaptation of needy and poor citizens."

In the Republic of Bashkortostan, the tasks are formulated as follows: "Increasing the level of incomes of citizens and exceeding the growth rate of incomes of citizens, including average wages, over the rate of inflation", "Development of a system of social assistance to citizens in need", "Development of a system of social contract", " Organization of social adaptation of poor citizens "," Stabilization of prices for consumer goods and services. " To achieve this goal, the regional program of the Kirov region defines the following tasks: "increasing the level of income of citizens and exceeding the growth rate of income of citizens, incl. average wages, over the rate of inflation; development of a system of social 
assistance to citizens in need; development of a system of state social assistance on the basis of a social contract; organization of social adaptation of low-income citizens".

\section{Results}

On the basis of the content analysis of the regional programs, it was determined, that despite the existing variability of formulations, according to the semantic load, the tasks of all regional programs can be combined into four blocks:

- an increase in the level of income of citizens and an excess of the growth rate of income of citizens, including average wages, over the rate of growth of inflation;

- development of a system of social assistance to citizens in need;

- development of the social contract system;

- organization of social adaptation of low-income citizens.

As the result of the analysis of regional programs, it was found that the tasks for all regional programs, the implementation timeframes of which correspond to the terms of 20202030 , correspond to the goals set, contribute to the achievement of the expected results in building an effective system for removing citizens from a difficult life situation by ensuring sustainable growth of real cash income, improving the targeting of the provision of social support measures, promoting employment.

In the course of the examination, it was revealed that the choice of target indicators for various regional programs have varying degrees of elaboration.

For example, the regional program of the Stavropol Territory defines 36 indicators characterizing the income of the population, the level of regional poverty, the situation with employment and unemployment, investment activity, regional specifics of the development of small and medium-sized businesses, housing provision of low-income citizens, availability of educational and medical services, social assistance to low-income citizens, development of a social contract and social adaptation. All target indicators of the regional program are specific, do not allow double interpretation, and correspond to the goals and objectives of the program. At the same time, the calculation according to the target indicators "The number of high-performance jobs in the non-budgetary sector of the economy of the Stavropol Territory" require additional specification.

\section{Discussions}

Throughout the entire existence of the USSR, a significant part of the citizens was in a state of poverty or close to it. The existing planned consumption rates were based on the concept of a basic physical minimum consumption. In 1989, the State Statistics Committee set the subsistence level at 90 Soviet rubles. About 71 million people ( $24.8 \%$ of the population) had incomes below this baseline, that is, they could not meet their basic needs. An ineffective planned economy often could not fulfill its tasks and the supply of most regions of the RSFSR was insufficient. In view of this, the well-being of the absolute majority of citizens was low, even if their earnings exceeded the official subsistence minimum.

In the Russian Federation, the first attempts to study the working poor began in the 1990s. After the collapse of the USSR and the system of the planned economy, the mechanisms for the redistribution of resources in the economy ceased to work. The material situation of the majority of citizens has not changed much (with the exception of Moscow and St. Petersburg), but the rapid growth of income differentiation has led to an explosive growth in relative poverty.

A significant part of the citizens who felt their poverty after the collapse of the USSR and the increase in income differentiation are working poor. The risk zone of becoming working 
poor included citizens most connected with the public sector of the economy, namely the budget sector (education, culture, fundamental science, museums, theaters), employees of military-industrial complex enterprises, as well as older citizens who could not adapt to the new economic reality. as well as families with children.

The deterioration of the situation of these population groups occurred gradually. In most industries, problems began after 1992. The disproportions in the planned economy of the USSR became open after the collapse of the existing system. The working poor of the late Soviet era and the 1990s formed a stable social group - the Russian working poor. This led to the formation of this problem as a structural one, requiring long-term corrective work.

Abroad, poverty is one of the most demanded areas of scientific research. T. Smiding, C. Booth, S. Rountree, F. Hayek, T. Townsend, M. Orshanski, N. Mening, A. Sen and others made a significant contribution to the study of poverty and inequality. Many scientists have studied the problems of poverty in Russia, including: Bobkov V.N., Kuznetsova N.P., Ovcharova L.N., Razumov A.A., Roik V.D., Rimashevskaya N.M., Sarkisyan G.S., Surkov S.V., Tikhonova N.E., et al. In the sphere of interests of modern domestic science is the study of the factors causing the emergence of poverty, the sources of the formation of economic inequality, the problems of social inequality and social stratification, the peculiarities of social protection of the poor categories of citizens, the main directions of overcoming poverty, etc. At the same time, a number of issues related to poverty, still requires further study.

\section{Conclusion}

To conclude, the basis for the formation of a set of measures for regional poverty reduction programs are the results of the analysis of the standard of living in the constituent entities of the Russian Federation and the identification of the causes and characteristics of poverty.

The analysis of the standard of living in a constituent entity of the Russian Federation should contain such data as: indicators of socio-economic development; assessment of the impact of indicators characterizing the socio-economic development of the region and measures implemented within the framework of national projects in the field of demography, labour productivity and employment support, small and medium-sized businesses and support for individual entrepreneurial initiative, education and health care, to increase the income of the population and reduce the level of poverty; information on the real level and structure of poverty at the regional level and in the context of municipalities; factors and causes of poverty of families and citizens living alone (income level, dependency burden, health status, educational level, level of employment and unemployment, participation in social support programs, etc.); data on the period of the family's stay in a state of poverty (permanently or periodically due to extraordinary circumstances); characteristics of poverty in urban and rural areas; factors that determine the entry and chronic stay in the group of the poor; ranking citizens with incomes below the subsistence level, identifying the most vulnerable citizens with incomes below the subsistence level, whose social support is a priority; measures of social support at the regional level and in the context of municipalities; the practice of applying state social assistance on the basis of a social contract.

During the examination of regional programs, it was found that in most constituent entities of the Russian Federation, an assessment was made of indicators characterizing the socio-economic development of the region and measures implemented within the framework of national projects in the field of demography, labor productivity and employment support, small and medium-sized businesses and individual support. entrepreneurial initiative, education and health care, which have an impact on increasing incomes of the population and reducing poverty, there is information about the main measures of social support at the regional level and their impact on raising the income of low-income citizens. Among the 
most effective tools of social support, contributing to the early exit of families and citizens living alone from a difficult life situation in all regional programs, the practice of applying state social assistance on the basis of a social contract is noted.

At the same time, the degree of elaboration of the analysis of the current situation of the standard of living in the constituent entity of the Russian Federation in the studied program documents is very heterogeneous.

\section{References}

1. R. Breunig, O. Majeed, Inequality, poverty and economic growth. International Economics, 161, 83 (2020)

2. M. Cruz, S. A. Ahmed, On the impact of demographic change on economic growth and poverty. World Development, 105, 95 (2018)

3. A. Dhrifi, R. Jaziri, S. Alnahdi, Structural Change and Economic Dynamics, 52, 13 (2020)

4. D. Dollar, T. Kleineberg, A. Kraay, Policy research working paper 6568. World Bank, Washington, DC (2013)

5. A. Panori, L. Mora, A. Reid, Journal of Cleaner Production, 237, 117850 (2019)

6. G. Robles Aguilar, A. Sumner, World Development, 126, 104716 (2020)

7. J. Rozenberg, S. Hallegatte, Policy Research Working Paper. World Bank, Washington, DC (2017)

8. H. C. Winsemius, B. Jongman, T. I. E. Veldkamp, S. Hallegatte, M. Bangalore, P. J. Environment and Development Economics (2018) 